\title{
HISTORIA
}

\section{LA ENFERMERÍA Y LOS CUIDADOS EN LOS SELLOS DE ESPAÑA}

Antonio Manuel Ballesteros Álvaro

Enfermero.

Centro de Salud de Carrión de los Condes. (Palencia)

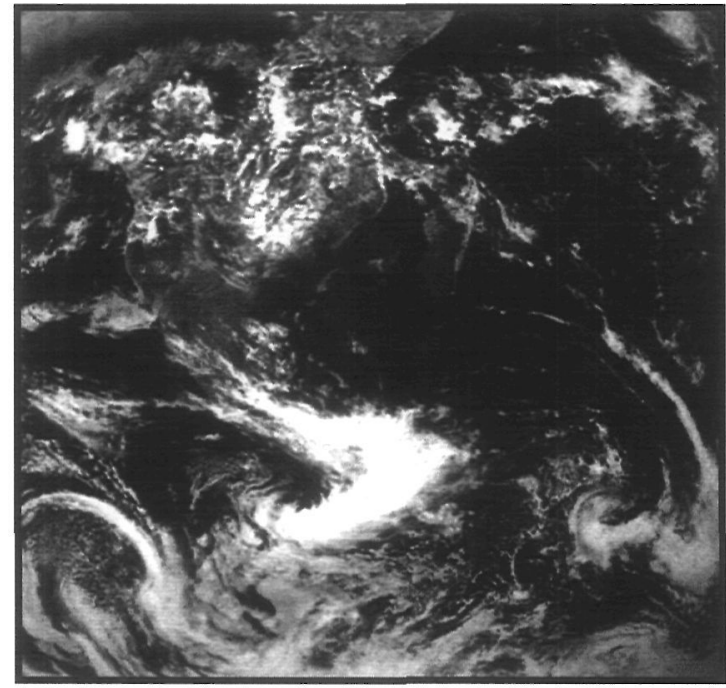

NURSING CARE: RECOGNITION IN THE SPANISH STAMPS

\section{SUMMARY:}

$\mathrm{T}$

The first post stamp in Spain was issued January 1 st, 1850 . Since then up to the present day, paramount people, celebrities, events... worth to be recognised and remembered world wide, have been given a public recognition in the stamp. Our work here tries to analyse 150 years of Spanish stamps, since the Nursing and caring point of view.

Key words: History of Nursing, stamp-collecting.

\section{RESUMEN.}

n España, el primer sello de correos se emite $\checkmark$ el 1 de Enero de 1850. Desde entonces y hasta la actualidad, en ellos se han representado a grandes personajes, acontecimientos,...que merecían un reconocimiento público. Pretendemos analizar estos 150 años de sellos en España, desde el punto de vista de la enfermería y los cuidados.

Palabras Clave: Historia de la enfermería, Filatelia.

\section{I.- INTRODUCCIÓN.}

Aunque el servicio de correos es muy antiguo, el primer sistema postal con franqueo previo se organizó en Paris en 1653; se llamó la Petit Poste y fue el intento de organizar la distribución del correo en la ciudad de Paris; aunque el sello, como tal, no aparecería hasta mediados del s. XIX. Hasta ese momento era el destinatario, y no el remitente, el que pagaba las tasas del correo y éstas se fijaban en función de la distancia entre el origen y el destino. La picaresca hacía que muchas veces se rechazaran "sobreescritos", argumentando su elevado precio; lo cierto es que el destinatario, sin necesidad de abrir el sobre sabía su contenido, gracias a símbolos escritos en él y que, mediante convenios previos, permitía la comunicación sin pagar las tasas. Sir Rowland Hill presenció en una ocasión, allá por el año 1836, uno de estos sucesos, lo que le llevó a idear un sistema de previo pago con tasas baratas.

En 1839 el plan se aprobó por parte del 
Parlamento británico previa aceptación del Post Office, y así en 1840, el 6 de Mayo, se puso en vigor el primer sello de correos en Inglaterra. Era la efigie de la reina Victoria sobre fondo negro (el "Penny Black"). Tras Gran Bretaña, la idea se aceptó en Suiza y Brasil (1843), Finlandia (1845), Estados Unidos (1847),... En España la reina Isabel II firmó el 24 de Octubre de 1849 el decreto que establecía en España el franqueo previo de la correspondencia, dicho decreto entró en vigor el 1 de Enero de 1850, y el primer sello emitido fue la efigie de Isabel II con un valor de 6 cuartos.

Desde el mismo momento de su aparición comenzó el interés por el coleccionismo de sellos. El primer coleccionista conocido fue un inglés, el Doctor Gray (1841). En España se considera a D. Santiago Ángel Saura como el primer coleccionista de sellos español en 1850. El vocablo filatelia fue propuesto por el francés M.G. Herpin el 15 de noviembre de 1864 y era derivado del griego philos (amigo) y atelia (previo pago).

Desde entonces, en los sellos se ha reflejado gran parte de la historia de un país, costumbres, celebraciones, aniversarios, personajes, etcétera, otorgando con ello un reconocimiento social a quien en ellos aparece. El presente estudio pretende conocer como se han reflejado la enfermería y los cuidados en los sellos emitidos en España, desde 1850 y hasta el año 2000. Estos 150 años de sellos son los que pretendemos analizar.

\section{II.- MATERIAL Y MÉTODOS.}

Para la realización de este estudio descriptivo se analizaron catálogos de sellos, sellos de colecciones privadas y también se consultó en la página http: //w.w.w. Correos.es, para visitar los fondos del museo postal y telegráfico, desde el año 1850 y hasta el año 2000.

Se realizó así mismo, una concienzuda búsqueda bibliográfica en las bases de datos CUIDEN y CUIDATGE, pero los artículos encontrados sobre el tema eran escasos.

Para seleccionar los distintos sellos que aquí aparecen se tuvieron en cuenta personajes, acontecimientos, escenas,... que tuvieran algún tipo de relación con la enfermería y los cuidados y se comentaron al seleccionar dicho sello.
Probablemente, el criterio de selección podría variar de unas personas a otras, pero objetivamente, considero que los sellos que aquí se recogen comparten todos los criterios de inclusión necesarios para formar parte de esta selección. El resultado de todo ello es lo que a continuación se expone.

\section{III.- RESULTADOS.}

Aunque el primer sello de correos se emite en España el 1 de Enero de 1850, no es hasta 1926, con motivo de una emisión Pro Cruz Roja Española, que aparece un sello con alguna vinculación con la enfermería. Dicho sello (sello n ${ }^{\circ} 1$ ), era de 2 céntimos de color azul y representaba a la reina Victoria Eugenia con uniforme de enfermera". Posteriormente, este sello volvió a emitirse en 1927 con valor de 50 céntimos, color naranja y sobrecargado. El mismo sello volvió a aparecer sobrecargado con un valor de 5 Ptas. ese mismo año. La Cruz Roja se funda el 22 de Agosto de 1864 con el fin de aglutinar los recursos necesarios para hacer frente a los heridos de las guerras. Ese mismo año se crea un Comité Nacional de la Cruz Roja Española. Con el paso del tiempo se crearían Escuelas de Enfermeras de la Cruz Roja para la enseñanza especializada. El mismo año de la creación del título de enfermera en España (1915) se hace el primer examen para enfermeras por parte de la Cruz Roja, examen que aprobaron 43 alumnas. Posteriormente se creará en España el cuerpo de Damas Enfermeras de la Cruz Roja. Sirvan estas pinceladas como argumento de la importancia que tuvo la Cruz Roja para la evolución de la enfermería Española.

En 1934-35 se emite una serie dedicada a diversos personajes, entre ellos Dña. Concepción Arenal. Esta mujer fue la gran reformadora de la enfermería española del s. XIX; una enfermería, hasta esos momentos, con escasos conocimientos culturales y penuria material, como consecuencia de la falta de personal enfermero, derivado de la desamortización. Se dedican a ella dos sellos de 15 céntimos, uno en verde-azul y otro en gris-negro. En 1937 se vuelve a emitir el mismo sello, esta vez en color verde-amarillo. (Sello $\left.n^{\circ} 2\right)$

En 1938, el 1 de junio se emite un sello de Cruz Roja Española de 45 cts. más 5 Ptas. en color rojo- 
naranja. (Sello n ${ }^{\circ}$ ) Posteriormente se sobrecargó con 3 Ptas. para correo aéreo.

En 1950, cien años después del primer sello en España, se emite, el 8 de marzo uno dedicado al IV Centenario de la muerte de San Juan de Dios (Sello $n^{0} 4$ ). Este portugués, afincado en Granada, decidió abandonar las armas para dedicarse a cuidar a los más enfermos y necesitados. Fundó un pequeño hospital que se mantenía gracias a la caridad y en el que recogió y cuidó enfermos, ancianos, niños y locos. Es hoy día el patrono de la enfermería. El sello emitido con este motivo es de 1 Ptas. y de color violeta.

En 1953, el 1 de Octubre se emite una serie Pro Tuberculosos, en ella, en el valor de 10cts., y en color verde con la cruz de Lorena en rojo, aparece una enfermera vacunando a un niño. (Sello $\mathrm{n}^{\circ} 5$ )

En 1960, el 27 de Septiembre, se emiten dos sellos (Sello $n^{\circ} 6$ ) con valor de 25 cts. y 1 Ptas. en colores violeta y naranja respectivamente. Su motivo era el III Centenario de la muerte de San Vicente Paul. Este monje franciscano fundó en Francia en el s. XVII las Hermanas de la Caridad, unas monjas que realizaban una función de enfermería completa, prestando atención domiciliaria a pobres y enfermos, realizando labores de enfermería en hospitales, recogiendo huérfanos. Eran para los Hospitales, un personal fiable puesto que reunían moralidad, virtud y una buena preparación técnica. Son pues uno de los paradigmas de la enfermería y para muchos el origen moderno de la profesión.

E1 28 de octubre de 1963 se emite un sello multicolor de 1 Ptas. en conmemoración del Centenario de la Cruz Roja Internacional. En él se ve la asistencia a los heridos en conflictos a través de una triple escena que representa la parábola del Buen Samaritano según ilustración del Códice Aureo de El Escorial. (Sello ${ }^{\circ} 7$ )

En la navidad de 1971 y en la de 1972 se emitieron, como suele ser habitual, sellos alusivos al tema. El sello de 1971 "El Nacimiento" (Sagars), con una valor de 8 Ptas. representa a la Virgen María recostada tras haber dado a luz a Jesús, mientras es, quizá, cuidada por San José. (Sello n ${ }^{\circ}$ 8) En 1972, el sello emitido tenía un valor de 2 Ptas. y representaba a la Virgen, postrada tras el nacimiento, con una mujer (una matrona de la época) que, presumiblemente, le ha ayudado en el parto. (Sello $\mathrm{n}^{\circ}$ 9) Este tema de la Natividad es muy recurrente, pues siempre se emiten series conmemorativas de la misma al finalizar cada año y es fácil encontrar ejemplares representando "algún tipo de cuidado" hacia la Virgen o el Niño.

El 29 de Septiembre de 1978, en una emisión dedicada a Pablo Ruiz-Picasso, se representa su famoso cuadro titulado "Ciencia y Caridad". Este cuadro, pintado por Picasso cuando contaba tan solo con 15 años, representa a una madre moribunda que es atendida por un médico (la ciencia) y por una monja (la caridad). Mientras el médico toma el pulso en la mano mortecina de la paciente, la monja-enfermera sostiene en brazos a su hijo a la vez que le ofrece un vaso de agua. En este cuadro Picasso supo plasmar con maestría, a pesar de su corta edad, los diferentes roles de cada profesión. (Sello $n^{\circ}$ 10)

En 1987, el 4 de Marzo, sello dedicado a la Lactancia materna con un valor de 19 Ptas. E1 tema era la supervivencia infantil, gran problema en muchos países del mundo. La UNICEF quiso dejar patente que uno de los cuatro pilares básicos para reducir esta alta mortalidad es la lactancia materna. Desde los diferentes sistemas sanitarios tenemos una gran responsabilidad en informar de la importancia de este hecho, y la enfermería en esta función de educación sanitaria, tiene un insustituible papel que desempeñar. (Sello $n^{\circ} 11$ )

El 20 de mayo de 1989, con motivo de la Exposición Filatélica Nacional, se emite la Hoja Bloque que contiene el sello con el cuadro "La Sagrada Familia con Santa Ana" (también llamado "Virgen de la Buena Leche"), pintado por El Greco en el periodo 1587-1597. En él, la Virgen María en presencia de San José y de su madre, Santa Ana, amamanta a Jesús. Dicho sello tenía un valor de 20 Ptas. (Sello $n^{\circ} 12$ )

En 1990, el 19 de junio, dedicada a los Centenarios, se emite el sello II Centenario de la llegada a España de las Hijas de la Caridad. Dicho sello, con un valor de 8 Ptas., reproduce el cuadro titulado "Caridad" de Alfredo López Alonso en el que tres monjas atienden a un anciano caído en la calle. Una vez que San Vicente Paul hubo fundado, en 1633, la "Escuela de Caridad" en Francia bajo 
el lema "Vuestros amos y señores son los pobres", las muchachas que allí ingresaban se preparaban durante ocho años para el trato y cuidado de los enfermos. En 1790 llegan a Barcelona las seis primeras "Hijas de la Caridad" que vinieron a desarrollar su labor asistencial a España. (Sello $n^{\circ} 13$ )

En 1996, el 8 de Marzo, se emite un sobre entero postal (aunque no es un sello, es también un producto filatélico) dedicado al $\mathrm{V}$ Centenario del Nacimiento de San Juan de Dios. Llevaba un sello de 30 Ptas. con la efigie de SM. Don Juan Carlos I en azul cobalto y oro. (Figura 14)

\section{CONCLUSIONES.}

Si la aparición de un personaje o actividad en los sellos de correos es un reconocimiento social hacia esa persona o hacia esa profesión, hemos de concluir que la enfermería, así como las personas que contribuyeron a hacer de ella lo que es, tiene en España ese reconocimiento. Quizá parezca poco que en 150 años sólo se hayan podido encontrar 14 documentos filatélicos referidos a nuestra profesión, pero hemos de tener en cuenta que desde la emisión del primer sello y hasta el comienzo de la Guerra Civil (en total 86 años) la mayor parte de las personas aparecidas en los sellos formaban parte de la Familia Real o eran personajes españoles de fama mundial (Colón, Cervantes, Goya,...). Que en este periodo haya un sello con alusiones a la enfermería puede considerarse un privilegio. En los 64 años restantes aparecieron 13 sellos lo que no es un mal porcentaje.

Hecho este primer comentario, si que es de destacar que algunos de los acontecimientos que han marcado la profesión enfermera en España hayan quedado sin su correspondiente representación en los sellos, por ejemplo, la creación de la primera escuela de enfermería en España (1896), cuyo centenario se "celebró" recientemente, la creación del título oficial de enfermera en 1915 o la unificación de las tres disciplinas (matronas, practicantes y enfermeras) que formaron la profesión, o la creación de los Colegios Profesionales (otros colectivos como médicos, arquitectos,... tienen en los sellos su correspondiente alusión).

No obstante concluiré afirmando que la enfermería, tanto en su historia como en los cuidados que presta, tienen una más que aceptable representación en la filatelia española; bien es cierto que en otros países esta presencia de la enfermería en los sellos es mayor que aquí, quizá por una mejor concienciación de las personas con alguna representatividad dentro del colectivo enfermero. Al igual que se lucha con otros medios para lograr un mayor reconocimiento social de la enfermería, el sello como tal, brinda una gran oportunidad de dar a conocer la profesión a miles y miles de personas que lo usan en su vida cotidiana. Esperemos que los representantes de nuestra profesión no dejen escapar oportunidades de aparecer en ellos, lo que contribuirá sin duda a un mayor acercamiento a la sociedad.

\section{BIBLIOGRAFÍA.}

- Gran Larousse Universal (1995). Voz "Sello de correos", Páginas 11433-11434. Editorial Plaza y Janés.

- Soler Vilá, J.M.(1976). Los sellos de las Olimpiadas. Edita Nutrexpa. Barcelona.

- Briggs M. (1992) Sellos. Editorial Debate.

- Catálogo de sellos de España (1999). Edita Servicio Filatélico de Correos y Telégrafos de España.

- Siles González, J. (1999). Historia de la enfermería. Consejo de Enfermería de la Comunidad Valenciana.

- Comelles, J.M. (2000) "Curar y cuidar. Bases para una historia antropológica de la enfermería hospitalaria". Revista ROL de Enfermería no 172. Pág. 35-41

- Miralles Sangro, M.T. (1995). San Juan de Dios y su Orden en la Filatelia. Index de Enfermería. otoño. IV (14); 59-61.

- Miralles Sangro, M.T.; Casas Martínez, M $^{a}$ F.(1995). Una forma diferente de recuperar nuestra historia: el reconocimiento social a la enfermera. II Jornadas de Documentación científica y cuidados de Salud. Granada. 
Sello $\mathbf{n}^{0} 12$

Exfilna '89. Toledo: "La Sagrada Familia con

Sta. Ana" de El Greco.

Fecha de Emisión: 20 de Mayo de 1989

Tirada: 3.000 .000 (Sello procedente de Hoja Bloque)

Valor: 20 ptas.

Sello $\mathrm{n}^{0} 13$ Centenarios: II Centenario de las Hijas de la Caridad. "Caridad" de Alfredo López Alonso

Fecha de emisión: 19 de Junio de 1990

Tirada: 3.000 .000

Valor: 8 ptas.

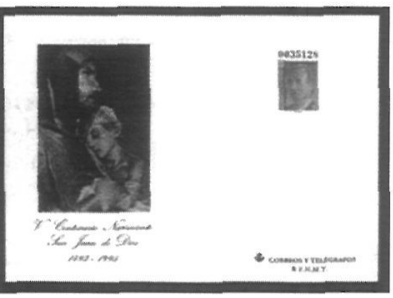

Figura $\mathbf{n}^{0} 14$.

Sobre entero postal

V Centenario del nacimiento de San Juan de Dios.

Granada

Sello: Azul cobalto y oro. Valor 30 ptas 